\title{
Hubungan antara Kepribadian Narsistik dengan Sikap terhadap Perselingkuhan pada Individu Dewasa Awal yang telah Menikah
}

\author{
WELDA ARUM LESTARI \& HAMIDAH* \\ Fakultas Psikologi Universitas Airlangga
}

\begin{abstract}
ABSTRAK
Penelitian ini bertujuan untuk menguji hubungan antara kepribadian narsistik dengan sikap terhadap perselingkuhan pada individu dewasa awal yang telah menikah. Tingginya tingkat perceraian di Indonesia yang dilatarbelakangi oleh perselingkuhan, serta adanya penelitian mengenai kecenderungan berselingkuh pada individu narsistik yang menarik perhatian peneliti untuk melihat hubungan keduanya. Penelitian ini menggunakan survei online dengan teknik purposive sampling pada 189 orang yang terdiri dari 87 laki-laki dan 102 perempuan dengan kriteria usia dewasa awal 21-39 tahun, telah menikah dan tidak poligami atau poliandri. Alat ukur dalam penelitian ini ialah Narcisistic Personality Inventory (NPI-40) dan Attitudes Towardss Infidelity Scale. Hasil yang didapatkan dari analisis uji korelasi dengan teknik spearman's rho menunjukkan nilai korelasi sebesar 0,212 dan nilai signifikansi sebesar 0,003. Berarti terdapat hubungan positif yang signifikan namun lemah antara kepribadian narsistik dengan sikap terhadap perselingkuhan dalam pernikahan.
\end{abstract}

Kata kunci: dewasa awal, kepribadian narsistik, pernikahan, sikap terhadap perselingkuhan

\begin{abstract}
This study aims to examine the relationship between narcissistic personality and attitudes towardss infidelity in early adult married individuals. The high divorce rate in Indonesia which is motivated by infidelity, and the existence of research on the tendency to have an affair with narcissistic individuals that attracts researchers' attention to see the relationship between the two. This study used an online survey with a purposive sampling technique on 189 people consisting of 87 men and 102 women with the criteria of early adulthood 21-39 years old, married and monogamy. Measurement tools in this study are NPI-40 and Attitudes Towardss Infidelity Scale. The results obtained from the correlation test analysis with the technique Spearman's rho showed a correlation value of 0.212 and a significance value of 0.003 . This means that there is a significant but weak positive relationship between narcissistic personality and attitudes towardss infidelity in marriage.
\end{abstract}

Keywords: attitudes towardss infidelity, early adulthood, marriage, narcissistic personality

Buletin Penelitian Psikologi dan Kesehatan Mental (BRPKM), 2021, Vol. 1(1), 678-686

*Alamat korespondensi: Fakultas Psikologi Universitas Airlangga, Kampus B Universitas Airlangga Jalan Airlangga 4-6 Surabaya 60286. Surel: hamidah@psikologi.unair.ac.id

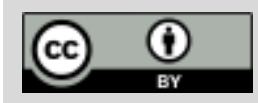

Naskah ini merupakan naskah dengan akses terbuka dibawah ketentuan the Creative Common Attribution License (CC-BY-4.0) (http://creativecommons.org/licenses/by/4.0), sehingga penggunaan, distribusi, reproduksi dalam media apapun atas artikel ini tidak dibatasi, selama sumber aslinya disitir dengan baik. 


\section{PE N D A H U L UA N}

Pernikahan merupakan hubungan antara laki-laki dan perempuan dewasa dalam ikatan khusus berdasarkan tatanan sosial dan hukum untuk mencapai beberapa tujuan masyarakat. Pernikahan ialah komitmen yang tidak hanya melibatkan perorangan tetapi banyak pihak. Masyarakat memandang pernikahan sebagai ikatan yang permanen dan sulit untuk dibatalkan (Ponzetti, 2003). Definisi pernikahan yang tertuang dalam Undang-Undang RI Nomor 1 tahun 1974 tentang Perkawinan Bab I Pasal 1, yakni ikatan lahir batin antara seorang pria dengan seorang wanita sebagai suami-istri dengan tujuan membentuk keluarga yang bahagia dan kekal berdasarkan Ketuhanan Yang Maha Esa (Wibisana, 2016). Regulasi usia minimal pernikahan telah diatur dalam UU nomor 16 Tahun 2019 pasal 7 ayat 1 yang berbunyi "Perkawinan hanya diizinkan apabila pria dan wanita sudah mencapai umur 19 tahun". Pernikahan yang bahagia mampu meningkatkan kesehatan serta memperpanjang hidup seseorang. Berbanding terbalik dengan itu, pernikahan yang tidak bahagia memberikan efek buruk terhadap kesehatan. Penelitian yang dilakukan Coontz (2005 dalam Howe, 2015) yang menemukan bahwa kesehatan seseorang yang berada dalam pernikahan tidak bahagia lebih buruk daripada seorang lajang. Pernikahan yang tidak bahagia biasanya disebabkan oleh konflik yang terjadi dalam pernikahan. Konflik yang terjadi dapat berasal dari dalam maupun dari luar pernikahan. Pasangan yang tidak dapat menyelesaikan konflik dengan baik seringkali memutuskan untuk berpisah (Emery, 1999).

Fenomena perceraian yang terjadi di Indonesia mengalami kenaikan dari tahun ke tahun, menurut data yang dihimpun oleh Badan Pusat Statistik (bps.go.id) terdapat kenaikan sebesar 23.000 kasus perceraian dari tahun 2013 sampai tahun 2015 (detikNews, 2020). Angka perceraian di Jatim naik dari 84 ribu kasus menjadi 88 ribu kasus pada tahun 2018. Perceraian diakibatkan oleh banyak faktor, umumnya masalah ekonomi, ketidakharmonisan hubungan, dan perselingkungan yang melatarbelakanginya. Perselingkuhan menjadi salah satu faktor paling banyak penyebab perceraian. Data dari Pengadilan Agama menunjukkan angka yang cukup signifikan sebanyak hampir 70\% perceraian yang terjadi di Indonesia sepanjang tahun 2007 disebabkan oleh perselingkuhan (detikNews, 2010). Sumber selanjutnya yang merujuk data dari Pengadilan Agama Depok mencatat dari 2.231 kasus perceraian di tahun 2017 menunjukkan sebanyak 1.862 perceraian terjadi karena adanya pihak ketiga alias perselingkuhan melalui media sosial, serta sebanyak 111 pasangan diketahui menggugat cerai karena alasan ekonomi dan sisanya bercerai karena berbagai masalah rumah tangga.

Perselingkuhan dijabarkan sebagai tindakan seksual atau emosional yang bertentangan dengan ketentuan yang telah disepakati bersama, namun dikhianati oleh salah satu orang yang terlibat dalam hubungan (Blow \& Hartnett, 2005). Perselingkuhan merupakan akibat dari suatu kegagalan yang terjadi pada intrapsikis dan interpersonal seseorang (Leone, 2013). Perselingkuhan dapat memberikan berbagai dampak negatif dalam suatu hubungan pernikahan, terutama pada pasangan yang menjadi korban. Menurut Schonian (2013), dampak perselingkuhan tersebut bisa berupa dampak terhadap kondisi fisik, emosional, dan juga hubungan itu sendiri. Perselingkuhan tidak akan memberikan dampak negatif terhadap pasangan jika tidak diketahui, bahkan akan memberikan pengalaman yang menyenangkan bagi pasangan yang berselingkuh. Namun saat perselingkuhan terungkap, hal tersebut akan menyulitkan kedua belah pihak baik pasangan yang menjadi korban maupun pelaku perselingkuhan (Glass \& Staeheli, 2003; Subotnik \& Harris, 2005 dalam Ginanjar, 2009). Pasangan akan merasa sakit hati dan kecewa karena komitmen yang mereka sepakati bersama dikhianati oleh salah satu pasangan. Komitmen ternyata memiliki dampak yang kuat pada keberlanjutan suatu hubungan. Ketika seseorang merasa komitmen pasangannya dipertanyakan, itu bisa menjadi faktor

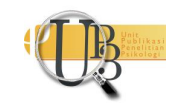


yang kuat dari pemutusan hubungan (Baron, dkk, 2008 dalam Isma \& Turnip, 2019). Identifikasi kecenderungan dan faktor predisposisi individu terhadap perselingkuhan sangat penting dalam memahami tanda-tanda perselingkuhan, yang kemudian memberikan gambaran suatu populasi yang berisiko menjadi tidak setia (Whisman, dkk, 2007 dalam Isma \& Turnip, 2019). Langkah awal yang dapat diambil untuk mengetahui gambaran individu yang berisiko menjadi tidak setia adalah dengan melihat sikapnya terhadap perselingkuhan karena sikap dapat mengarahkan kecenderungan individu untuk berperilaku tidak setia. Sikap bukan merupakan perilaku, tetapi sikap menghadirkan suatu kesiapsiagaan yang mengarah pada suatu perilaku. Menurut Ajzen (2005) sikap dapat memprediksikan perilaku individu terhadap suatu objek dan juga mampu meningkatkan pemahaman mengenai sebab individu menunjukkan atau gagal menunjukkan kecenderungan perilaku tertentu. Sehingga sikap terhadap perselingkuhan akan mengarahkan bagaimana seseorang berperilaku dari caranya memandang perselingkuhan.

Sikap terhadap perselingkuhan merupakan pemikiran, perasaan dan perilaku terhadap suatu perselingkuhan. Sikap tersebut dapat berupa permisif dan tidak permisif (Whatley, 2006). Menurut Whatley (2006) orang yang permisif terhadap perselingkuhan cenderung tidak setia. Treas dan Giesen (2000 dalam Blow \& Hartnett, 2005) juga menyebutkan individu yang memiliki sikap permisif terhadap perselingkuhan memiliki kecenderungan untuk berselingkuh.

Isma dan Turnip (2019) menjelaskan sikap terhadap perselingkuhan dapat dipengaruhi berdasarkan faktor demograsi, interpersonal dan intrapersonal. Hal yang terpenting dalam intrapersonal adalah kepribadian individu. Ciri kepribadian individu didefinisikan oleh McCae dan Costa (2003) sebagai dimensi perbedaan individu dalam kecenderungan untuk menunjukkan pola pikiran, perasaan dan tindakan yang konsisten. Kepribadian Narsistik merupakan salah satu faktor penyebab individu cenderung berselingkuh (Atkins dkk., 2005). Beberapa penelitian menyatakan individu dengan kepribadian narsistik cenderung terlibat dalam suatu perselingkuhan karena less empathy, less commitment, dan sebagainya. Penegasan yang paling umum adalah bahwa mereka dengan kesehatan psikologis yang buruk, mudah frustasi, masculine insecurity (untuk pria), dan narsistik lebih rentan terhadap perselingkuhan (Buunk \& van Driel, 1989 dalam Irawan \& Suprapti, 2018). Individu dengan kepribadian narsistik cenderung menyikapi perselingkuhan lebih permisif (Foster dkk., 2006). Hal ini didukung oleh penelitian yang dilakukan oleh Hunyady dkk. (2008) pada 316 partisipan pada mahasiswa sarjana (70 laki-laki, 246 perempuan) berpartisipasi dalam percobaan mengenai sikap terhadap perselingkuhan seksual, ditemukan bahwa pria dan orang dengan kepribadian narsistik lebih permisif terhadap perselingkuhan dibandingkan dengan wanita dan orang yang tidak narsistik. Buss dan Shackelford (1997 dalam Shimberg dkk., 2016) menjelaskan bahwa aspek kepribadian berhubungan dengan perselingkuhan, individu yang lebih narsistik telah terbukti kurang setia daripada yang tidak. Hasil penelitian Shimberg dkk. (2016) tentang empati menjelaskan pria dan individu dengan kepribadian narsistik memiliki empati yang rendah, sehingga lebih toleran terhadap perselingkuhan daripada mereka yang tidak memiliki kecenderungan narsistik.

Treas \& Giesen (2000 dalam Blow \& Hartnett, 2005) menyarankan pentingnya meneliti sikap terhadap perselingkuhan karena individu yang memiliki sikap permisif terhadap perselingkuhan memiliki kecenderungan untuk berselingkuh. Penelitian yang saat ini berkembang pada konteks kepribadian narsistik dan sikap terhadap perselingkuhan masih minim dilakukan di Indonesia. Meninjau dari segi karakteristik budaya tentunya memiliki perbedaan kondisi antara di luar negeri dan di Indonesia. Mengingat kembali tingginya angka kasus perceraian di Indonesia yang disebabkan oleh perselingkuhan, disinilah peneliti ingin mendalami lebih lanjut fenomena tersebut dalam melihat hubungan kepribadian narsistik dengan sikap terhadap perselingkuhan. Hal ini perlu untuk dilakukan 
sebagai langkah preventif agar tingkat perceraian yang diakibatkan oleh perselingkuhan kedepannya tidak terus mengalami peningkatan. Pertanyaan dalam penelitian ini berfokus pada seberapa besar hubungan antara Kepribadian Narsistik dengan Sikap terhadap Perselingkuhan pada individu dewasa awal yang telah menikah.

\section{Desain Penelitian}

\section{E T O D E}

Penelitian yang digunakan dalam penelitian ini ialah kuantitatif korelasional. Metode penelitian mengumpulkan banyak data untuk melihat gambaran besar dari suatu hal sehingga lebih objektif dalam memandang suatu fakta. Teknik pengambilan data dalam penelitian ini menggunakan metode survei, karena dalam penelitian ini ingin melihat hubungan antara beberapa variabel. Pengumpulan data dilakukan dengan menyebarkan kuesioner secara online melalui Google Form. Kuesioner dibagi menjadi empat bagian yaitu informed consent, data demografis, skala Sikap terhadap Perselingkuhan dan skala Narcissistic Personality Inventory (NPI-40) untuk mengukur tingkat kepribadan narsistik. Uji validitas penelitin ini menggunakan content validity dengan bantuan professional judgement. Pengukuran reliabilitas menggunakan teknik Alpha Cronbach. Analisis data menggunakan uji korelasi nonparametrik dengan teknik Spearman's Rho. Pengolahan dan analisis data dilakukan menggunakan program SPSS for windows versi 20.

\section{Partisipan}

Partisipan dalam penelitian ini dibatasi dengan menganalisis data sekunder dengan pengambilan populasi pada individu yang memenuhi karakteristik laki-laki atau perempuan, usia dewasa awal antara 21-39 tahun, sudah menikah dan tidak berpoligami atau poliandri. Sampel penelitian didasarkan pada teknik pengambilan sampel secara non-probability sampling, yaitu purposive sampling. Purposive sampling dipergunakan untuk mengambil sampel yang dilakukan dengan mengambil orang-orang tertentu menurut ciri-ciri spesifik yang dimiliki oleh sampel itu. Penentuan jumlah sample yang digunakan mengacu pada rumus rules of thumb $\mathrm{n} \geq 50+8(\mathrm{~m})$ dimana " $\mathrm{m}$ " adalah jumlah variabel independen. Maka dari itu, jumlah sampel yang harus dipenuhi minimal 58 orang atau lebih.

Penulis merekrut 189 partisipan untuk menguji hipotesis penelitian ini, dengan gambaran partisipan 87 orang laki-laki (46\%) dan perempuan berjumlah 102 orang (54\%). Selain itu, gambaran partisipan berdasarkan usia yakni 138 orang berusia 21-30 tahun (73\%) dan 51 orang berusia 31-39 tahun (27\%). Kemudian gambaran berdasarkan tingkat pendidikan paling banyak ialah perguruan tinggi sejumlah 152 orang (80\%), diikutin tingkat SMA sebanyak 34 orang 18\%, sedangkan tingkat pendidikan lainnya hanya terwakilkan 1 partisipan masing-masing.

\section{Pengukuran}

Penelitian ini menggunakan skala pengukuran yang dirancang oleh Raskin \& Terry (1988) mengungkapkan seberapa besar tingkat narsistik pada populasi normal. Narcissistic Personality Inventory Scale menggunakan kuesioner pilihan sebanyak 40 pilihan yang mengungkapkan tingkat individu pada kepribadian narsistik untuk setiap aitem. Partisipan diharapkan memilih salah satu dari dua pernyataan pada setiap aitem yang sesuai atau mendekati dengan dirinya. Skala pengukuran ini pernah digunakan Uthaug (2018) dalam penelitiannya mengenai sikap terhadap perselingkuhan. Skala ini terdiri dari 23 aitem favorable dan 17 aitem unfavorable. Sedangkan untuk melihat sikap terhadap perselingkuhan penulis menggunakan skala pengukuran Attitudes Towards Infidelity Scale milik

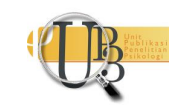


Whatley (2006). Skala ini dikembangkan oleh Whatley (2006) untuk menilai apakah individu menyetujui atau tidak menyetujui perselingkuhan yang dilakukan, dimana terdapat skala 1 sampai 7 poin, yaitu 1 untuk sangat tidak setuju hingga 7 yaitu sangat setuju. Semakin tinggi skor yang didapat maka akan semakin setuju terhadap perselingkungan, sebaliknya, jika skor rendah maka akan semakin tidak setuju terhadap perselingkuhan. Skala ini sudah pernah digunakan Dianty (2017) dalam penelitiannya mengenai perbedaan variable ini ditinjau dari prior experience.

Uji validitas skala pengukuran penelitian ini didasarkan pada validitas isi (content validity). Validitas isi dalam penelitian ini diperoleh melalui analisis rasional berupa pendapat dan masukan individu profesional atau yang berkompeten (professional judgement/rater) yang dalam penelitian ini adalah dosen-dosen pengajar di bidang Psikologi maupun praktisi Psikologi. Reliabilitas dalam penelitian ini dilihat dari nilai koefisien Cronbach's alpha. Nilai reliabilitas NPI-40 sebesar 0,878 dan reliabilitas sikap terhadap perselingkuhan sebesar 0,848.

Skor skala pengukuran diperoleh dengan cara dijumlah. Peneliti harus melakukan uji asumsi terlebih dahulu sebelum akhirnya dapat menentukan uji parametrik atau non parametrik yang akan digunakan dalam penelitian ini. Uji asumsi yang pertama ialah uji normalitas. Hasil uji normalitas diketahui bahwa taraf signifikansi variabel sikap terhadap perselingkuhan 0,000 dan variable kepribadian narsistik 0,009. Maka dari itu, dapat ditarik kesimpulan bahwa kedua variabel tersebut berdistribusi tidak normal karena nilai taraf signifikansinya $<0,05$.

\section{Analisis Data}

Uji analisis menggunakan uji korelasi non-parametrik dengan teknik Spearman's Rho. Pengolahan dan analisis data dilakukan menggunakan program SPSS for windows versi 20.

\section{HAS I L P E N EL I T IAN}

Hasil analisis deskriptif menunjukkan jumlah $(\mathrm{N}=189)$ partisipan yang dianalisa dari setiap skala. Skor terendah (Min) attitudes towardss infidelity dari data partisipan sebesar 11 sedangkan nilai tertingginya (Max) 72 dan rata-rata (Mean) sebesar 24,61. Nilai terendah (Min) narcissistic personality inventory adalah 1, nilai tertingginya (Max) adalah 39, dan rata-rata (Mean) sebesar 14,10. Partisipan yang memperoleh skor rendah pada skala attitudes towardss infidelity sebanyak 7,9\% dengan jumlah 15 responden. Selanjutnya partisipan yang memiliki skor sedang berjumlah 153 orang dengan persentase $80 \%$, dan yang memperoleh skor tinggi ada 21 responden dengan persentase 11,1\%. Selain itu, partisipan yang memiliki skor rendah pada skala narcissistic personality inventory sama persis dengan partisipan yang memperoleh skor tinggi yakni berjumlah 28 dengan persentase sebesar 14,8\%. Partisipan yang memperoleh skor sedang berjumlah 133 dengan persentase 70,4\%.

Hasil analisis korelasi diketahui bahwa kepribadian narsistik berkorelasi positif dan berkekuatan lemah $(r(189)=0,212 \mathrm{p}<.003)$ dengan sikap terhadap perselingkuhan.

\section{I S K U S I}

Analisis uji korelasi yang telah dilakukan menunjukkan hasil koefisien korelasi yang didapatkan sebesar 0,212 yang berarti terdapat hubungan positif yang signifikan namun lemah antara kepribadian narsistik dengan sikap terhadap perselingkuhan. Hubungan positif disini diartikan bahwa jika semakin tinggi skor kepribadian narsistik semakin tinggi pula skor sikap terhadap perselingkuhan, maka semakin

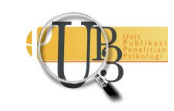


tinggi tingkat kepribadian narsistik seseorang akan semakin permisif terhadap perselingkuhan, begitupun sebaliknya. Hasil dari analisis korelasi juga menemukan adanya hubungan dengan melihat taraf signifikansinya. Signifikansi dalam penelitian ini sebesar, 0,003. Nilai signifikansi yang lebih kecil dari 0,05 menunjukkan bahwa hipotesis alternatif dalam penelitian ini diterima, sedangan hipotesis nul ditolak.

Beberapa hasil dari penelitian terdahulu memperkuat hasil dari penelitian ini. Hunyady dkk. (2008) menemukan hasil yang sama pada penelitiannya mengenai narsitik, dimana orang dengan tingkat kepribadian narsistik yang tinggi cenderung lebih permisif terhadap perselingkuhan dibandingkan dengan individu yang memiliki skor kepribadian narsistik yang rendah. Selain itu, Shimberg dkk. (2016) menjelaskan hasil dari penelitiannya bahwa pria dan individu yang memiliki kepribadian narsistik tinggi ternyata memiliki empati yang rendah, hal itu membuat mereka lebih memaklumi perselingkuhan daripada individu yang tidak cenderung memiliki kepribadian narsistik. Willis dkk. (2017) juga menemukan hasil yang serupa, jika hasil skor kepribadian narsistik individu tinggi, maka ia juga akan semakin toleran terhadap perselingkuhan. Individu yang mementingkan diri sendiri dan memiliki empati yang rendah mungkin lebih toleran terhadap ketidaksetiaan dalam hubungan monogami yang berkomitmen. Sikap yang menoleransi perselingkuhan mungkin merupakan manifestasi pemikiran seksual yang memandang seks sebagai instrumen.

Penelitian ini juga menemukan bahwa nilai rata-rata kepribadian narsistik laki-laki lebih tinggi dibandingkan dengan hasil nilai rata-rata perempuan. Begitu pula nilai rata-rata sikap terhadap perselingkuhan, laki-laki memiliki nilai yang lebih tinggi dari perempuan. Hal tersebut sejalan dengan penelitian Hunyady dkk. (2008) yang menyatakan bahwa laki-laki dan individu narsistik lebih toleran terhadap perselingkuhan dibandingkan wanita. Lieberman menemukan bahwa responden perempuan, lebih tidak setuju terhadap perselingkuhan seksual dibandingkan laki-laki. Nilai rata-rata berdasarkan usia pernikahan juga ditemukan tinggi pada kelompok usia pernikahan 6-10 tahun. Berdasarkan penelitian Booth (2009) usia pernikahan yang rentan mengalami pereceraian ialah usia pernikahan diatas 6 tahun dan sering disebabkan oleh mulai menurunnya ketidakpuasan pernikahan. Ketidakpuasan pernikahan merupakan salah satu faktor yang memunculkan sikap permisif terhadap perselingkuhan (Isma \& Turnip, 2019; Watkins \& Boon, 2016)

Namun hasil penelitian ini memperlihatan kekuatan hubungan yang lemah, hal tersebut mungkin dipengaruhi karena banyaknya faktor yang mempengaruhi sikap. Kepribadian bukan satu-satunya faktor, ada faktor demografis dan juga faktor interpersonal (Isma \& Turnip, 2019). Sikap terhadap perselingkuhan tampaknya berbeda karena pengaruh interaksi dengan variabel lain. Variabel ini meliputi budaya jenis kelamin, jenis hubungan primer (misalnya, heteroseksual, lesbian, kencan, pernikahan), perilaku yang membentuk perselingkuhan (misalnya, hubungan seksual, hubungan cinta), dan pengalaman sebelumnya dengan perselingkuhan (Blow \& Hartnett, 2005).

\section{S I M P U L A N}

Berdasarkan dari analisis yang telah dilakukan dalam penelitian ini diperoleh hasil yang menunjukkan adanya hubungan signifikan antara kepribadian narsistik dengan sikap terhadap perselingkuhan. Meski begitu kekuatan hubungan kedua variabel masih lemah karena adanya faktor lain yang mempengaruhi sikap. Kepribadian narsistik diketahui berhubungan positif dengan sikap terhadap perselingkuhan, yang berarti semakin tinggi nilai kepribadian narsistik individu maka semakin tinggi pula nilai sikap 
terhadap perselingkuhan. Jadi dalam penelitian ini orang yang cenderung memiliki kepribadian narsistik akan lebih permisif terhadap perselingkuhan.

Hasil penelitian ini dapat digunakan sebagai wawasan baru terkait dengan salah satu faktor yang menyebabkan kecenderungan perselingkuhan sangat beragam salah satunya kepribadian narsisik yang mengarah pada sikap permisif terhadap perselingkuhan, sehingga dapat mengantisipasi dinamika dalam pernikahan. Hasil dari penelitian ini juga dapat menjadi pertimbangan melakukan konsultasi pranikah pada konselor pernikahan sebagai bentuk preventif dalam membangun sebuah pernikahan. Penulis menyarankan agar penelitian selanjutnya lebih memperdalam dan memperkaya kajian teoritik mengenai topik yang serupa. Mempertimbangkan faktor-faktor lain yang masih belum digali. Sehingga mampu memperkaya literatur yang masih sedikit. Hasil penelitian ini diharapkan bisa memberikan informasi kepada konselor perkawinan mengenai faktor kepribadian narsistik sebagai salah satu faktor determinan dari sikap terhadap perselingkuhan pada individu dewasa awal. Sehingga dapat melengkapi gambaran permasalahan klien terkait perselingkuhan dan membantu mencari jalan keluar untuk masalah tersebut.

\section{U C A P A N T E R I M A K A S I H}

Terima kasih saya ucapkan kepada Allah SWT, orang tua, dosen pembimbing, keluarga dan temanteman yang telah mendukung dan membantu penulis selama proses penelitian. Terima kasih juga saya ucapkan kepada pemilik alat ukur sikap terhadap perselingkuhan yang mengizinkan saya memakai alat ukurnya serta memberikan ringkasan tulis miliknya. Terima kasih saya juga untuk para partisipan yang mau membantu saya untuk menyelesaikan penelitian ini.

\section{DEKLARAS I POTENSI TERJADINYA KONFLIK KEPENTINGAN}

Welda Arum Lestari dan Hamidah tidak bekerja, menjadi konsultan, memiliki saham, atau menerima dana dari perusahaan atau organisasi manapun yang mungkin akan mengambil untung dari diterbitkannya naskah ini.

\section{PUSTAKA ACUAN}

Ajzen, I. (2005). Attitudes, personality, and behavior. Open. University Press.

Atkins, D. C., Baucom, D. H., Yi, J., \& Christensen, A. (2005). Infidelity in couples seeking marital therapy. In Journal of Family Psychology (Vol. 19, Issue 3). https://doi.org/10.1037/0893-3200.19.3.470

Blow, A. J., \& Hartnett, K. (2005). April 2005 JOURNAL OF MARITAL AND FAMILY THERAPY 217 INFIDELITY IN COMMITTED RELATIONSHIPS II: A SUBSTANTIVE REVIEW. Journal of Marital and Family, 31(2), 217-233.

Booth, L. M. (2009). Commitment communication and length of marriage: Scratching the seven-year itch. Proceedings of the 5th Annual GRASP Symposium, Wichita State University, 16-17.

detikNews. (2010, Februari 22). Selingkuh Penyebab 10 Ribu Kasus Perceraian, Poligami Hanya 937

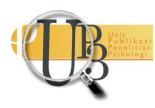


Kasus. Retrieved Desember 15, 2019, from detikNews: https://news.detik.com/berita/d1304065/selingkuh-penyebab-10-ribu-kasus-perceraian-poligami-hanya-937-kasus

detikNews. (2020, Februari 28). Nyaris Setengah Juta Janda Baru Lahir di Indonesia Sepanjang 2019. Retrieved Juni 9, 2020, from detiknews: https://news.detik.com/berita/d-4918371/nyarissetengah-juta-janda-baru-lahir-di-indonesia-sepanjang-2019

Emery, E. (1999). Marriage, Divorce and Children Adjustment (2nd ed.). Prentice Hall International.

Foster, J. D., Shrira, I., \& Campbell, W. K. (2006). Theoretical models of narcissism, sexuality, and relationship commitment. Journal of Social and Personal Relationships, 23(3), 367-386. https://doi.org/10.1177/0265407506064204

Ginanjar, A. S. (2009). Proses Healing Pada Istri Yang Mengalami Perselingkuhan Suami. Makara, Sosial Humaniora, 13, 66-76.

Howe, T. R. (2015). Marriages and families in the 21st century: A bioecological approach. In Marriages and Families in the 21st Century: A Bioecological Approach. https://doi.org/10.1002/9781444344714

Hunyady, O., Josephs, L., \& Jost, J. T. (2008). Priming the primal scene: Betrayal trauma, narcissism, and attitudes towards sexual infidelity. Self and Identity, 7(3). https://doi.org/10.1080/15298860701620227

Irawan, M. N. S., \& Suprapti, V. (2018). Hubungan Antara Kematangan Emosi dan Intensi Berselingkuh Pada Individu Dewasa Awal yang Sudah Menikah. Jurnal Psikologi Pendidikan Dan Perkembangan, 7.

Isma, M. N. P., \& Turnip, S. S. (2019). Personality Traits and Marital Satisfaction in Predicting Couples' Attitudes Towards Infidelity. Journal of Relationships Research, 2011. https://doi.org/10.1017/jrr.2019.10

James J. Ponzetti, J. (2003). International Encyclopedia of Marriage and Family. In MACMILLAN REFERENCE USA (2nd ed.). Macmillan Reference USA. https://doi.org/10.1017/9781576472682.011

Leone, C. (2013). Helping Couples Heal From Infidelity: A Self Psychological, Intersubjective Approach. International Journal of Psychoanalytic Self Psychology, 8(3). https://doi.org/10.1080/15551024.2013.796608

McCae, R. R., Costa, P. T., \& JR. (2003). Personality in Adulthood. In Personality in Adulthood. The Guilford Press. https://doi.org/10.4324/9780203428412

Raskin, R., \& Terry, H. (1988). A Principal-Components Analysis of the Narcissistic Personality Inventory and Further Evidence of Its Construct Validity. Journal of Personality and Social Psychology, 54(5). https://doi.org/10.1037/0022-3514.54.5.890

Shimberg, J., Josephs, L., \& Grace, L. (2016). Empathy as a Mediator of Attitudes Towards Infidelity

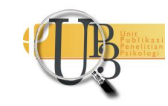


Among College Students. Journal of Sex and Marital Therapy, 42(4). https://doi.org/10.1080/0092623X.2015.1053019

Watkins, S. J., \& Boon, S. D. (2016). Expectations regarding partner fidelity in dating relationships. Journal of Social and Personal Relationships, 33(2), 237-256. https://doi.org/10.1177/0265407515574463

Whatley, M. (2006). Attitude towards Infidelity scale.

Wibisana, W. (2016). Pernikahan dalam Islam. Jurnal Pendidikan Agama Islam - Ta'lim, 14(2).

Willis, M., Birthrong, A., King, J. S., Nelson-Gray, R. O., \& Latzman, R. D. (2017). Are infidelity tolerance and rape myth acceptance related constructs? An association moderated by psychopathy and narcissism. Personality and Individual 117. https://doi.org/10.1016/j.paid.2017.06.015 